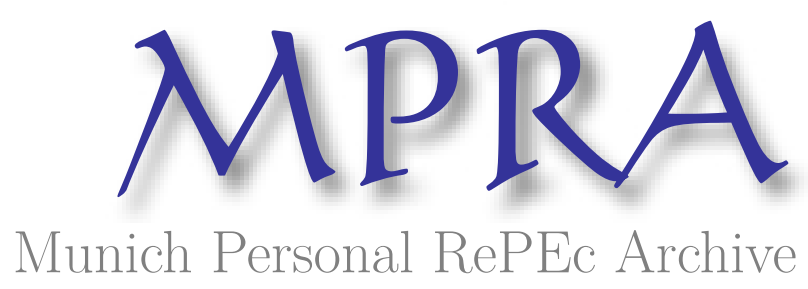

\title{
Financial openness and the size of the public sector: a portfolio approach
}

Erauskin-Iurrita, Inaki

University of Deusto-ESTE School of Management

15 September 2008

Online at https://mpra.ub.uni-muenchen.de/10619/

MPRA Paper No. 10619, posted 19 Sep 2008 11:00 UTC 


\title{
Financial openness and the size of the public sector: a portfolio approach
}

\author{
Iñaki Erauskin-Iurrita * \\ University of Deusto-ESTE
}

3rd September 2008

\begin{abstract}
A good deal of time has been devoted to whether more open economies have bigger governments. However, most of the research has been focused mainly on trade openness, which is clearly restrictive in an increasingly integrated world. This paper offers an alternative view to the relationship between financial openness and some key economic variables (the size of the public sector, ...), based on a portfolio approach. A central result of the model is that an open economy implies a higher consumption-wealth ratio, lower growth, higher welfare, and a higher size of the public sector than in a closed economy due to the risk diversification that an open economy allows. The empirical evidence broadly supports the main results of the model.

JEL classification: F41; F43

Keywords: Financial openness; consumption-wealth ratio; growth; welfare; optimal size of the public sector.
\end{abstract}

*Department of Economics, Apartado 1359, 20080 Donostia-San Sebastián, Spain. Email: ineraus@ud-ss.deusto.es. I deeply thank Javier Gardeazabal for all his help. I also thank Cruz Ángel Echevarría, Asier Minondo, Inma Muñoa, Jesús Vázquez, PhD Thesis Examination Committee members, and seminar participants at the XXVIII Simposio de Análisis Económico, at the Brown Bag organized at the University of the Basque Country, and at the 59th European Meeting of the Econometric Society for their very helpful suggestions and comments. The financial support of Gipuzkoako Foru Aldundia is gratefully acknowledged. The remaining errors and omissions are entirely my responsibility. 


\section{Introduction}

Do more open economies have bigger governments? A good deal of time has been devoted to this issue since Rodrik (1998) hit the magic button showing a positive relationship between both variables: "government expenditures are used to provide social insurance against external risk" (p. 997) ${ }^{1}$. Many other studies have followed suit and some of them have even cast doubts on the robustness of the result ${ }^{2}$. However, the main focus of most of the research has been on trade openness. This is clearly restrictive specially when financial markets are becoming increasingly integrated ${ }^{3}$.

Liberati (2007) has recently reminded that, from a theoretical perspective, openness can be associated to a larger or lower size of the public sector ${ }^{4}$. According to the compensation hypothesis, more open economies have a larger size of the public sector to compensate for higher external risk. In contrast, the efficiency hypothesis (or conventional wisdom) posits that more open economies are associated to a lower size of the public sector due to an increased mobility of inputs. Furthermore, "as it stands, $[. .$.$] the empirical$ literature on the relationship between capital openness and government size is not conclusive, as different studies support a positive relation, the absence of any relation or a negative relation." (pp. 218-219). Thus Liberati (2007, p. 215) shows that "capital openness is significantly and negatively related to government expenditures in line with the conventional wisdom that capital mobility may undermine the ability of governments to maintain larger public sectors". Moreover, the recent empirical evidence does not seem to support the compensation hypothesis proposed by Rodrik (1998).

This paper offers an alternative view to the relationship between financial openness and some key economic variables, such as the consumption-wealth ratio, the growth rate of wealth, welfare, and the optimal size of the public sector, based on a portfolio approach. The model employed is an extension of the one developed by Turnovsky [1997, Ch. 11; 1999]: a general equilibrium model in continuous time with perfect capital mobility in a two-country world, where public spending enhances utility (Barro, 1990). A central result of our model is that an open economy implies a higher consumption-wealth ratio, lower growth, higher welfare, and a higher size of the public sector than in a closed economy due to the risk diversification that an open economy

\footnotetext{
${ }^{1}$ The pioneer work of the "compensation hypothesis" goes back at least to Cameron (1978).

${ }^{2}$ See Liberati (2007) for references.

${ }^{3}$ See, for instance, Lane and Milesi-Ferretti (2007).

${ }^{4}$ See Schulze and Ursprung (1999) for the original work.
} 
allows $^{5}$. The critical differences with previous studies are twofold. First, financial integration is not necessarily associated to higher external risk due to the risk diversification effect. Second, financial openness is measured as the share of the holdings of foreign capital owned by the domestic economy over domestic wealth. Instead, the literature has usually chosen the sum of (some) domestic assets and liabilities with respect to other countries over $\mathrm{GDP}^{6}$. The recent availability of data on investment positions allows testing the main results of the model ${ }^{7}$. The empirical evidence based on a sample of 22 OECD countries for the period 1970-2004 broadly supports the main results of the model.

The outline of the paper is as follows. In Section 2 the macroeconomic equilibrium is characterized. In Section 3 the results of an open economy are compared to those of a closed economy. The welfare-maximizing size of the public sector is derived in Section 4. Then we discuss whether more open economies will have a higher size of the public sector in Section 5. Section 6 provides the empirical evidence. Finally, we conclude.

\section{The world economy}

\subsection{Basic structure}

The world economy consists of two countries, each of them producing only one homogeneous good. On each country there exist a representative agent and a public sector, both with an infinite time horizon. This economy is a real one, that is, there are no nominal assets, such as money, different financial assets, etc. Unstarred variables refer to domestic economy, whereas starred variables refer to the foreign economy. This model will focus on the domestic economy since the results for the foreign economy are very similar.

The homogeneous good produced by both countries can be either consumed or invested in capital without having to incur in any kind of adjustment

\footnotetext{
${ }^{5}$ As Obstfeld and Taylor (2004, p. 5) put it, "economic theory leaves no doubt about the potential advantages of global financial trading," such as allowing international risk sharing and intertemporal trade, and imposing discipline on governments.

${ }^{6}$ See Lane and Milesi-Ferretti (2007) and Liberati (2007), for example. An important exception is Turnovsky $(1999$, p. 889), where the size of the public sector is shown to be higher in a small open economy than in a closed economy if and only if the country is net creditor, when the utility function is logarithmic: "the larger government is due to the country's ability to export its domestic risk, rather than due to insulating the country from foreign risks". However, his model has not been empirically tested.

${ }^{7}$ The data is mainly provided by the International Monetary Fund, and Lane and Milesi-Ferretti (2007).
} 
costs. We assume that domestic production can be obtained using only domestic capital, $K$, through an $A K$ function, and that it can be expressed through a first order stochastic differential equation, so that production flow $d Y$ (the variation of the state variable) is not completely determined, but subject to a stochastic disturbance

$$
d Y=\alpha K d t+\alpha K d y
$$

where $\alpha>0$ is the (constant) marginal physical product of capital and $d y$ represents a proportional domestic productivity shock. More precisely, $d y$ is the increment of a stochastic process $y$. Those increments are temporally independent and are normally distributed, and they satisfy that $E(d y)=0$ and $E\left(d y^{2}\right)=\sigma_{y}^{2} d t$. We omit, for convenience, formal references to time, although those variables depend on time. We must note that $d Y$ indicates the flow of production, instead of $Y$, as is ordinarily done in stochastic calculus.

The foreign economy is structured symmetrically to the domestic economy. Thus, foreign production is carried out using capital domiciled abroad, $K^{*}$, with a production function very similar to the one in the domestic economy

$$
d Y^{*}=\alpha^{*} K^{*} d t+\alpha^{*} K^{*} d y^{*}
$$

where $\alpha^{*}>0$ is the marginal physical product of capital and $d y^{*}$ represents a proportional foreign productivity shock. We should note that $d y^{*}$ is the increment of a stochastic process $y^{*}$. Those increments are temporally independent and are distributed normally, satisfying that $E\left(d y^{*}\right)=0$ and that $E\left(d y^{*^{2}}\right)=\sigma_{y^{*}}^{2} d t$.

Both domestic capital, $K$, and foreign capital, $K^{*}$, can be owned by the domestic agent or the foreign agent. The subscript $d$ denotes the holdings of assets of the domestic agent and the subscript $f$ denotes the holdings of assets of the foreign agent. So it must be satisfied that

$$
\begin{aligned}
K & =K_{d}+K_{f} \\
K^{*} & =K_{d}^{*}+K_{f}^{*} .
\end{aligned}
$$

The wealth of the domestic agent, $W$, and the wealth of the foreign agent, $W^{*}$, therefore will be

$$
\begin{aligned}
W & =K_{d}+K_{d}^{*} \\
W^{*} & =K_{f}+K_{f}^{*} .
\end{aligned}
$$




\subsection{Domestic economy}

\subsubsection{The maximization problem}

The preferences of the domestic representative agent are represented by a constant elasticity of substitution (or isoelastic) intertemporal utility function where she obtains utility from private consumption, $C$, and from public consumption, $G$

$$
\begin{gathered}
E_{0} \int_{0}^{\infty} \frac{1}{\gamma}\left(C G^{\eta}\right)^{\gamma} e^{-\beta t} d t \\
-\infty<\gamma<1 ; \eta>0 ; \gamma \eta<1 ; \gamma(1+\eta)<1 .
\end{gathered}
$$

The welfare of the domestic agent in period 0 is the expected value of the discounted sum of instantaneous utilities, conditioned on the set of disposable information in period 0 . The parameter $\beta$ is a positive subjective discount rate (or rate of time preference). For the isoelastic utility function the ArrowPratt coefficient of relative risk aversion is given by the expression $1-\gamma$. When $\gamma=0$ this function corresponds to the logarithmic utility function. The empirical evidence suggests a high degree of relative risk aversion, so that $\gamma<0$ (Campbell, 1996). The parameter $\eta$ measures the influence of public consumption on welfare. We assume that both private consumption and public consumption generate a positive marginal utility, so that $\eta>0$. The other restrictions on the utility function are necessary to ensure concavity with respect to private consumption and public consumption.

The domestic agent consumes at a deterministic rate $C(t) d t$ in the instant $d t$ and must pay the corresponding taxes and thus the dynamic budget restriction can be expressed in the following way

$$
d W=\left[\alpha K_{d}+\alpha^{*} K_{d}^{*}\right] d t+\left[\alpha K_{d} d y+\alpha^{*} K_{d}^{*} d y^{*}\right]-C d t-d T,
$$

where $d T$ denotes the taxes the domestic representative agent must pay to the public sector. The structure of taxes will be detailed below.

There is a public sector besides the domestic representative agent. Public sector spending, $d G$, increases with wealth, so we can achieve a balanced growth path. ${ }^{8}$ Public spending evolves according to

$$
d G=g W d t+W d z
$$

\footnotetext{
${ }^{8}$ Other rules can also achieve a balanced growth path. See Turnovsky (1996) for more details.
} 
where $g=G / W$ is the size of the public sector and $d z$ is the increment of a stochastic process $z$. Those increments are temporally independent and are normally distributed, satisfying that $E(d z)=0$ and $E\left(d z^{2}\right)=\sigma_{z}^{2} d t$. Public sector spending is financed solely via tax collection: the public sector equilibrates its budget continuously, that is,

$$
d T=d G
$$

Combining equations (5) and (6), and plugging them into (4), we get the following restriction for the resources of the domestic economy

$$
d W=\left[\alpha K_{d}+\alpha^{*} K_{d}^{*}-C-g W\right] d t+\left[\alpha K_{d} d y+\alpha^{*} K_{d}^{*} d y^{*}-W d z\right] .
$$

Let us remember that the holding of assets by the domestic agent is subject to the domestic wealth equation (1). If we define the following variables for the domestic agent

$$
\begin{aligned}
n_{d} \equiv & \frac{K_{d}}{W}=\text { share of the domestic portfolio materialized } \\
& \text { in domestic capital } \\
n_{d}^{*} \equiv & \frac{K_{d}^{*}}{W}=\text { share of the domestic portfolio materialized } \\
& \text { in foreign capital, }
\end{aligned}
$$

equation (1) can be expressed more conveniently as

$$
1=n_{d}+n_{d}^{*}
$$

and substituting those variables into the budget constraint (7) we obtain the following dynamic restriction for the resources of the domestic economy

$$
\frac{d W}{W}=\left[\alpha n_{d}+\alpha^{*} n_{d}^{*}-\frac{C}{W}-g\right] d t+\left[\alpha n_{d} d y+\alpha^{*} n_{d}^{*} d y^{*}-d z\right]
$$

This equation can be more conveniently expressed as

$$
\frac{d W}{W}=\psi d t+d w
$$


where the deterministic and stochastic parts of the rate of accumulation of assets, $d W / W$, can be expressed in the following way

$$
\begin{aligned}
\psi & \equiv n_{d}\left[\alpha-\alpha^{*}\right]+\alpha^{*}-g-\frac{C}{W} \equiv \rho-g-\frac{C}{W} \\
d w & \equiv n_{d}\left[\alpha d y-\alpha^{*} d y^{*}\right]+\alpha^{*} d y^{*}-d z,
\end{aligned}
$$

where $\rho \equiv \alpha n_{d}+\alpha^{*} n_{d}^{*} \equiv n_{d}\left[\alpha-\alpha^{*}\right]+\alpha^{*}$ denotes the gross rate of return of the asset portfolio.

\subsubsection{Equilibrium}

Now the case where the public sector acts as a central planner is analyzed. The objective of the central planner consists in choosing the path of private consumption and portfolio shares that maximizes the expected value of the intertemporal utility function (3) of the domestic representative agent, subject to $W(0)=W_{0},(10),(11)$, and (12). This optimization is a stochastic optimum control problem. ${ }^{9}$ Initially we assume that the public sector establi-shes an arbitrarily exogenous size of the public sector, $g$. We analyze the case in which such a size is chosen optimally in section 4 .

The macroeconomic equilibrium is derived in Appendix A. The equilibrium portfolio shares and the consumption-wealth ratio in the domestic open economy are given by

$$
\begin{aligned}
n_{d}= & \frac{\alpha-\alpha^{*}}{[1-\gamma(1+\eta)] \Delta}+\frac{\alpha^{*^{2}} \sigma_{y^{*}}^{2}-\alpha \alpha^{*} \sigma_{y y^{*}}+\alpha \sigma_{y z}-\alpha^{*} \sigma_{y^{*} z}}{\Delta} \\
n_{d}^{*}= & 1-n_{d} \\
\left(\frac{C}{W}\right)_{o}= & \frac{1}{(1-\gamma)(1+\eta)}[\beta-\gamma(1+\eta)(\rho-g) \\
& \left.+0.5 \gamma(1+\eta)[1-\gamma(1+\eta)] \sigma_{w, o}^{2}\right]
\end{aligned}
$$

where

$$
\begin{aligned}
\Delta= & \alpha^{2} \sigma_{y}^{2}-2 \alpha \alpha^{*} \sigma_{y y^{*}}+\alpha^{*^{2}} \sigma_{y^{*}}^{2} \\
\sigma_{w, o}^{2}= & n_{d}^{2} \alpha^{2} \sigma_{y}^{2}+2 n_{d} n_{d}^{*} \alpha \alpha^{*} \sigma_{y y^{*}}+n_{d}^{*^{2}} \alpha^{*^{2}} \sigma_{y^{*}}^{2}+\sigma_{z}^{2} \\
& -2 n_{d} \alpha \sigma_{y z}-2 n_{d}^{*} \alpha^{*} \sigma_{y^{*} z} .
\end{aligned}
$$

\footnotetext{
${ }^{9}$ To solve problems of stochastic optimum control see, for example, Kamien and Schwartz (1991, Section 22), Malliaris and Brock (1982, Ch. 2), Obstfeld (1992), or Turnovsky (1997, Ch. 9; 2000, Ch. 15).
} 
Do note that neither the expression $\Delta$ nor the variance of the rate of accumulation of domestic assets, $\sigma_{w, o}^{2}$, can be negative and the variables with the subscript $o$ refer to values in an open economy. Appendix B shows that the second order conditions are satisfied.

Then, the equilibrium rate of wealth accumulation of the open domestic economy follows the stochastic process

$$
\frac{d W}{W}=\psi_{o} d t+d w_{o}
$$

where the deterministic and stochastic components are, respectively

$$
\begin{aligned}
\psi_{o}= & \frac{1}{(1-\gamma)(1+\eta)}\{(1+\eta)(\rho-g)-\beta \\
& \left.-0.5 \gamma(1+\eta)[1-\gamma(1+\eta)] \sigma_{w, o}^{2}\right\} \\
d w_{o}= & n_{d} \alpha d y+n_{d}^{*} \alpha^{*} d y^{*}-d z .
\end{aligned}
$$

Even though with more general utility functions the optimal portfolio shares and consumption-wealth ratio will be functions of time, in this model all those variables are constant because the utility function exhibits constant relative risk aversion, the production function is linear, and the mean and variances of the underlying stochastic processes are stationary: the equilibrium is characterized by balanced real growth, where all the (real) assets grow at the same rate, and by constant consumption-wealth ratio and portfolio shares. The result is very similar to Turnovsky $(1997$, ch. 11). The same is also true for the foreign economy, as we shall see below. ${ }^{10}$

Now we describe the behavior of the domestic economy if it were closed in order to compare the results of an open economy with those of a closed economy later on. In a model of perfect capital mobility such as this, where domestic and foreign assets are traded without restrictions, we use the shares of the domestic portfolio materialized in domestic and foreign capital, $n_{d}$ and $n_{d}^{*}$ respectively, to approximate the degree of openness of the domestic economy. Since our emphasis is on the trade of assets, then we call closed economy the situation where there is no trade of assets. However, we should bear in mind that what we call closed economy is compatible with positive amounts of exports and imports, but subject to the restriction that the trade of goods must be balanced. In the case of a closed economy, the equilibrium solution will be given by the expressions

\footnotetext{
${ }^{10}$ We refer to Turnovsky $(1997,2000)$ for a standard review of the impact of changes in exogenous variables on the consumption-wealth ratio, portfolio shares, the growth rate, and welfare.
} 


$$
\begin{aligned}
\left(\frac{C}{W}\right)_{c}= & \frac{1}{(1-\gamma)(1+\eta)}\{\beta-\gamma(1+\eta)(\alpha-g) \\
& \left.+0.5 \gamma(1+\eta)[1-\gamma(1+\eta)] \sigma_{w, c}^{2}\right\} \\
\sigma_{w, c}^{2}= & \alpha^{2} \sigma_{y}^{2}+\sigma_{z}^{2}-2 \alpha \sigma_{y z} \\
\psi_{c}= & \frac{1}{(1-\gamma)(1+\eta)}\{(1+\eta)(\alpha-g)-\beta \\
& \left.-0.5 \gamma(1+\eta)[1-\gamma(1+\eta)] \sigma_{w, c}^{2}\right\} \\
d w_{c}= & \alpha d y-d z
\end{aligned}
$$

where the variables with the subscript $c$ refer to values in a closed economy.

\subsection{Welfare}

Economic welfare is measured by the value function we have used to solve the problem of intertemporal optimization, given by equation (45) in Appendix $\mathrm{B}$

$$
V(W)=\frac{g^{\eta \gamma}}{\gamma(1+\eta)}\left(\frac{C}{W}\right)^{\gamma-1} W^{\gamma(1+\eta)} .
$$

From the total differential of equation (23) we obtain, after some algebra, that

$$
\frac{d V}{V}=(\gamma-1) \frac{d(C / W)}{C / W}+\gamma \eta \frac{d g}{g},
$$

where we can observe that changes in the optimal consumption-wealth ratio and the (exogenous) size of the public sector have an impact on welfare.

First, a higher optimal consumption-wealth ratio can improve or deteriorate the welfare of the domestic economy. That is due to the fact that the value function can take either positive or negative values, depending on the sign of the coefficient $\gamma$. Since $C / W$ and $g$ are positive in equation (23) then $\gamma V(W)>0$. For the case $\gamma<0$, anything that increases the optimal consumption-wealth ratio raises welfare. Thus, for example, a higher subjective discount rate, increasing the optimal consumption-wealth ratio, generates higher welfare if $\gamma<0$.

Second, the size of the public sector is an important factor influencing welfare. Do note that the optimal consumption-wealth ratio, given by equation (15), also depends on the size of the public sector, $g$. Therefore, the 
impact of changes in the size of the public sector on welfare is given by

$$
\frac{d V}{V}=\gamma\left[\eta-\frac{g}{C / W}\right] \frac{d g}{g}
$$

Thus, a higher size of the public sector can increase or reduce welfare, even though it reduces unambiguously the growth rate. The crucial point lies on whether $g \lesseqgtr \eta C / W$. If $g<\eta C / W$, an increase in the size of the public sector raises welfare. That is due to the fact that the marginal utility derived from public consumption is higher than the marginal utility derived from private consumption. If $g=\eta C / W$, an increase in the size of the public sector does not change welfare because the marginal utility derived from public consumption is equal to the marginal utility derived from private consumption: it is the size of the public sector that maximizes welfare, as we shall see below. Finally, if $g>\eta C / W$, an increase in the size of the public sector reduces welfare because the marginal utility derived from public consumption is lower than the marginal utility derived from private consumption. These results are related to those in Turnovsky (2000, p. 438): "Thus we infer that increasing the growth rate by reducing government expenditure is not necessarily welfare improving. This will be the case only if initially $g$ is above its optimum". We shall see below that this is completely consistent with the analysis of the size of the public sector that maximizes welfare.

\subsection{Foreign economy}

\subsubsection{The maximization problem}

The problem facing the foreign representative agent can be formulated in an analogous way. Her preferences are represented by the following intertemporal utility function

$$
\begin{gathered}
E \int_{0}^{\infty} \frac{1}{\gamma^{*}}\left(C^{*} G^{*^{*}}\right)^{\gamma^{*}} e^{-\beta^{*} t} d t \\
-\infty<\gamma^{*}<1 ; \eta^{*}>0 ; \gamma^{*} \eta^{*}<1 ; \gamma^{*}\left(1+\eta^{*}\right)<1 .
\end{gathered}
$$

The equation of the rate of accumulation of wealth of the foreign representative agent can be expressed as

$$
\frac{d W^{*}}{W^{*}}=\psi^{*} d t+d w^{*}
$$

where 


$$
\begin{aligned}
\psi^{*} & \equiv n_{f} \alpha+n_{f}^{*} \alpha^{*}-g^{*}-\frac{C^{*}}{W^{*}} \equiv \rho^{*}-g^{*}-\frac{C^{*}}{W^{*}} \\
d w^{*} & \equiv n_{f} \alpha d y+n_{f}^{*} \alpha^{*} d y^{*}-d z^{*} .
\end{aligned}
$$

\subsubsection{Equilibrium}

The equilibrium portfolio shares and consumption-wealth ratio in the foreign economy are

$$
\begin{aligned}
n_{f}= & \frac{\alpha-\alpha^{*}}{\left[1-\gamma^{*}\left(1+\eta^{*}\right)\right] \Delta}+\frac{\alpha^{*^{2}} \sigma_{y^{*}}^{2}-\alpha \alpha^{*} \sigma_{y y^{*}}+\alpha \sigma_{y z^{*}}-\alpha^{*} \sigma_{y^{*} z^{*}}}{\Delta} \\
n_{f}^{*}= & 1-n_{f} \\
\left(\frac{C^{*}}{W^{*}}\right)_{o}= & \frac{1}{\left(1-\gamma^{*}\right)\left(1+\eta^{*}\right)}\left\{\beta^{*}-\gamma^{*}\left(1+\eta^{*}\right)\left(\rho^{*}-g^{*}\right)\right. \\
& \left.-0.5 \gamma^{*}\left(1+\eta^{*}\right)\left[\gamma^{*}\left(1+\eta^{*}\right)-1\right] \sigma_{w^{*}, o}^{2}\right\}
\end{aligned}
$$

where

$$
\begin{aligned}
\sigma_{w^{*}, o}^{2}= & n_{f}^{2} \alpha^{2} \sigma_{y}^{2}+2 n_{f} n_{f}^{*} \alpha \alpha^{*} \sigma_{y y^{*}}+n_{f}^{*^{2}} \alpha^{*^{2}} \sigma_{y^{*}}^{2} \\
& +\sigma_{z^{*}}^{2}-2 n_{f} \alpha \sigma_{y z^{*}}-2 n_{f}^{*} \alpha^{*} \sigma_{y^{*} z^{*}} .
\end{aligned}
$$

The equilibrium rate of accumulation of wealth in the foreign economy follows the stochastic process

$$
\frac{d W^{*}}{W^{*}}=\psi_{o}^{*} d t+d w_{o}^{*}
$$

where its deterministic and stochastic components are, respectively

$$
\begin{aligned}
\psi_{o}^{*}= & \frac{1}{\left(1-\gamma^{*}\right)\left(1+\eta^{*}\right)}\left\{\left(1+\eta^{*}\right)\left(\rho^{*}-g^{*}\right)-\beta^{*}\right. \\
& \left.-0.5 \gamma^{*}\left(1+\eta^{*}\right)\left[\gamma^{*}\left(1+\eta^{*}\right)-1\right] \sigma_{w^{*},}^{2}\right\} \\
d w_{o}^{*}= & n_{f} \alpha d y+n_{f}^{*} \alpha^{*} d y^{*}-d z^{*} .
\end{aligned}
$$




\section{Open economy versus closed economy}

In order to compare the results of an open economy with those of a closed economy it is convenient to calculate the difference between the variance of the growth rate in an open economy and in a closed economy. Thus if we subtract equation (21) from equation (17) we obtain, after some algebra, that

$$
\sigma_{w, o}^{2}-\sigma_{w, c}^{2}=\Delta n_{d}^{*}\left(n_{d}^{*}-2 \widetilde{n}_{d}^{*}\right)
$$

where

$$
\widetilde{n}_{d}^{*}=\frac{\alpha^{2} \sigma_{y}^{2}-\alpha \alpha^{*} \sigma_{y y^{*}}-\alpha \sigma_{y z}+\alpha^{*} \sigma_{y^{*} z}}{\Delta},
$$

is the share of the domestic portfolio materialized in foreign capital that minimizes the variance of the growth rate given by equation (17).

\subsection{The consumption-wealth ratio}

Subtracting equation (20) from equation (15) we obtain, using equation (25), that, after some algebra,

$$
\left(\frac{C}{W}\right)_{o}-\left(\frac{C}{W}\right)_{c}=-\frac{1}{1-\gamma}\left\{0.5 \gamma[1-\gamma(1+\eta)] \Delta n_{d}^{*^{2}}\right\}
$$

The sign of the difference between both consumption-wealth ratios depends only on the value of the parameter $\gamma$. Thus, if $\gamma<0$, then the consumptionwealth ratio will be higher in an open economy than in a closed economy, provided that $n_{d}^{*} \neq 0$. An easy way to explain that result can be found, without loss of generalization, focusing on the case $n_{d}=\widetilde{n}_{d}$, where

$$
\widetilde{n}_{d}=1-\widetilde{n}_{d}^{*}=\frac{\alpha^{*^{2}} \sigma_{y^{*}}^{2}-\alpha \alpha^{*} \sigma_{y y^{*}}+\alpha \sigma_{y z}-\alpha^{*} \sigma_{y^{*} z}}{\Delta}
$$

denotes the share of the domestic portfolio materialized in domestic capital that minimizes the variance of the growth rate of wealth [equation (17)]. When $n_{d}=\widetilde{n}_{d}$ we know from equation (25) that the variance of the growth rate in an open economy is lower than in a closed economy, $\sigma_{w, o}^{2}<\sigma_{w, c}^{2}$. Totally differentiating equation (15) it can be easily shown that a reduction in the variance of the growth rate is equivalent to an increase in the gross rate of return of the asset portfolio, $\rho$, of $0.5[1-\gamma(1+\eta)]$. A higher gross 
rate of return of the asset portfolio, $\rho$, raises (reduces) consumption-wealth ratio if $\gamma<(>) 0$ and does not change if $\gamma=0$ [see equation (15) above]. The result depends on the sum of two opposite standard effects, substitution and income effects. A higher gross rate of return of the asset portfolio has always a negative substitution effect since consumption becomes less attractive whereas investment is more attractive. The income effect on the consumption-wealth ratio, originated by a higher gross rate of return of the asset portfolio, is equal to unity: it makes possible to raise both actual and future consumption. If $\gamma<(>) 0$, income (substitution) effect dominates substitution (income) effect and if $\gamma=0$ the two effects compensate each other. From here onwards whenever a result depends on the sign of the parameter $\gamma$, we shall only focus on the case where $\gamma<0$, for being the most relevant situation empirically (Campbell, 1996). Since a lower variance of the growth rate originates a stronger positive income effect than the negative substitution effect on the consumption-wealth ratio, then the consumptionwealth ratio in an open economy will be higher than in a closed economy for $\gamma<0$. In an open economy a higher level of welfare is achieved choosing a higher consumption-wealth ratio, provided that $\gamma<0$, as we saw in Section 2.3. Additionally, the higher the value of the optimal share of the domestic portfolio materialized in foreign capital, $n_{d}^{*}$, the higher the difference between the results of an open economy with those of a closed economy, other things being equal.

\subsection{The growth rate}

The growth rate in an open economy is compared to that in a closed economy departing from equation (11) corresponding to an open economy and subtracting from it that corresponding to a closed economy

$$
\psi_{o}-\psi_{c}=n_{d}^{*}\left(\alpha^{*}-\alpha\right)-\left[\left(\frac{C}{W}\right)_{o}-\left(\frac{C}{W}\right)_{c}\right]
$$

The growth rate in an open economy can be higher than, equal to or lower than that in a closed economy, depending on the signs of the two terms in (28). For example, we can establish focusing on the case where $\gamma<0$ (and $\left.n_{d}^{*}>0\right)$ that:

- If $\alpha \geq \alpha^{*}$, the growth rate in an open economy will be lower than that in a closed economy. The reason behind is that the consumption-wealth ratio in an open economy is higher than that in a closed economy and, additionally, if $\alpha \geq \alpha^{*}$ the gross rate of return of the asset portfolio 
in an open economy, $\rho$, is lower than or equal to the marginal physical product of the domestic capital.

- If $\alpha<\alpha^{*}$, the growth rate in an open economy can be higher than, equal to or lower than that in a closed economy.

Table 1 sums up the comparison between the growth rate in an open economy with that in a closed economy given by equation (28), for $n_{d}^{*}>0$. As Obstfeld (1994, p. 1327) puts it, "the mechanism linking global diversification to growth is the attendant world portfolio shift from safe, but low-yield, capital into riskier, high-yield capital," thus focusing on the case that $\alpha<\alpha^{*}$ to show that an open economy may raise growth. Turnovsky (1997, p. 438) goes along the same line, comparing the growth rate in a risky open economy with that in a riskless closed economy, for the case that $\alpha<\alpha^{*}$ and $\gamma=0$ : the growth rate raises unambiguously in an open economy. However, it becomes clear in Table 1 that risk sharing does not necessarily raise growth. In fact, as long as the marginal product of capital is similar across countries, for instance, then the growth rate will be higher in a closed economy than in an open economy. Only when the marginal product of foreign capital $\alpha^{*}$ is higher than the marginal product of domestic capital $\alpha$, an open economy may promote growth.

\subsection{Welfare}

It is easy to show that welfare is unambiguously higher in an open economy than in a closed economy, simply going back to the value function given by equation (23): the consumption-wealth ratio in an open economy will be higher than that in a closed economy for $\gamma<0$ [see equation (26)]. In fact, the result applies to all values of the parameter $\gamma$, thus reinforcing the conclusions reached by Obstfeld (1994, pp. 1326-1327): "international risk-sharing can yield substantial welfare gains through its positive effect on expected consumption growth." Similarly, Turnovsky (1997, pp. 438-439) has shown that "the higher growth rate more than offsets the additional risk, and the opportunity to invest in a higher return, higher risk foreign asset improves welfare," for the logarithmic case. However, we should note that the crucial factor behind welfare improvement stems from the risk sharing effect implied by financial integration, rather than from shifting portfolios from low risk-low yield assets to high risk-high yield assets in an open economy, as in Obstfeld (1994) or Turnovsky (1997). Therefore, financial openness raises unambiguously welfare in all cases, regardless of whether $\alpha \lesseqgtr \alpha^{*}$. 


\section{The optimal size of the public sector}

We have so far compared the results in an open economy with those in a closed economy assuming an exogenous size of the public sector. Now we obtain the size of the public sector that maximizes the welfare of the domestic representative agent or, for short, the optimal size of the public sector. Then the results of an open economy are compared to those of a closed economy.

Formally, the expression in the right hand side of the Bellman equation (38) in Appendix A is partially differentiated with respect to $g$, where $G=$ $g W$, to calculate the optimal size of the public sector

$$
\frac{\eta}{g} C^{\gamma}(g W)^{\eta \gamma}-V^{\prime}(W) W=0
$$

which combining with the first order condition equation (39) implies that the optimal size of the public sector, $\widehat{g}$, must satisfy the following condition

$$
\hat{g}=\eta \frac{C}{W}
$$

which is identical to Turnovsky (1996, p. 60; 1999, p. 888). ${ }^{11}$ Equation (29) implies that the marginal utility of public consumption must be equal to the marginal utility of private consumption when both public and private consumption are optimally chosen.

Combining equation (29) with (15) we can calculate the optimal size of the public sector, the consumption-wealth ratio, and the growth rate when public consumption is optimally chosen in an open economy

$$
\begin{aligned}
\hat{g}_{o}= & \frac{\eta}{[1-\gamma(1+\eta)](1+\eta)}\{\beta-\gamma(1+\eta) \rho \\
& \left.+0.5 \gamma(1+\eta)[1-\gamma(1+\eta)] \sigma_{w, o}^{2}\right\} \\
\left(\frac{C}{W}\right)_{o}= & \frac{1}{[1-\gamma(1+\eta)](1+\eta)}\{\beta-\gamma(1+\eta) \rho \\
& \left.+0.5 \gamma(1+\eta)[1-\gamma(1+\eta)] \sigma_{w, o}^{2}\right\} \\
\psi_{o}= & \frac{1}{1-\gamma(1+\eta)}\left\{\rho-\beta-0.5 \gamma(1+\eta)[1-\gamma(1+\eta)] \sigma_{w, o}^{2}\right\}
\end{aligned}
$$

\footnotetext{
${ }^{11}$ We should note that the optimal size of the public sector, $\hat{g}$, is not exactly identical to that shown in Turnovsky (1999). However, it is identical in the sense that in both cases the optimal ratio of public consumption to private consumption is given by $G / C=\eta$.
} 
Do note that whenever we refer to the optimal size of the public sector in general we will use the term $\widehat{g}$ and whenever we refer only to the optimal size in an open economy we will use $\widehat{g}_{o}$.

In addition, we obtain the optimal size of the public sector, the consumption-wealth ratio, and the growth rate when public consumption is optimally chosen in a closed economy

$$
\begin{aligned}
\hat{g}_{c}= & \frac{\eta}{[1-\gamma(1+\eta)](1+\eta)}\{\beta-\gamma(1+\eta) \alpha \\
& \left.+0.5 \gamma(1+\eta)[1-\gamma(1+\eta)] \sigma_{w, c}^{2}\right\} \\
\left(\frac{C}{W}\right)_{c}= & \frac{1}{[1-\gamma(1+\eta)](1+\eta)}\{\beta-\gamma(1+\eta) \alpha \\
& \left.+0.5 \gamma(1+\eta)[1-\gamma(1+\eta)] \sigma_{w, c}^{2}\right\} \\
\psi_{c}= & \frac{1}{1-\gamma(1+\eta)}\left\{\alpha-\beta-0.5 \gamma(1+\eta)[1-\gamma(1+\eta)] \sigma_{w, c}^{2}\right\}
\end{aligned}
$$

\subsection{Open economy versus closed economy}

Focusing first on the optimal size of the public sector, if we subtract equation (33) from equation (30) we obtain using equation (25), after some algebra, that

$$
\hat{g}_{o}-\hat{g}_{c}=-0.5 \eta \gamma \Delta n_{d}^{*^{2}} .
$$

The sign of the result in equation (36) depends only on the parameter $\gamma$ : the size of the public sector in an open economy will be higher than that in a closed economy for $\gamma<0$. Let us see why. Without loss of generalization, focusing again on the case $n_{d}=\widetilde{n}_{d}$, where $\widetilde{n}_{d}$ is the variance-minimizing share of the domestic portfolio [see equation (27)], the variance in the growth rate in an open economy is lower than that in a closed economy, $\sigma_{w, o}^{2}<\sigma_{w, c}^{2}$ [see equation (25)]. Since a reduction of the variance in the growth rate is equivalent to an increase in the gross rate of return of the asset portfolio, that, in turn, originates a stronger positive income effect on the public consumptionwealth ratio than the negative substitution effect: the size of the public sector in an open economy will be higher than in a closed economy. ${ }^{12}$ Furthermore, it is similar to the result shown in Turnovsky (1999) for a logarithmic utility function, provided that the domestic economy holds positive stocks of

\footnotetext{
${ }^{12}$ In addition, the higher the value of the optimal share of the domestic portfolio materialized in foreign capital, $n_{d}^{*}$, the higher the difference between the optimal size of the public sector in an open economy with that in a closed economy is.
} 
foreign capital in a small open economy. However, it should be emphasized that our result has been shown for empirically the most relevant case that $\gamma<0$, no matter what the values of portfolio shares are. On top of that, Turnovsky (1999, p. 889) bases his results on "the country's ability to export its domestic risk, rather than due to insulating the country from foreign risk, as argued by Rodrik [1998]." Instead, our argument resembles more Rodrik's (1998. p. 1011) "insulation function" against external risk rather than Turnovsky's "risk exporting" argument. However, while risk sharing is a key factor behind our result, Rodrik underlines the central role played by the public sector in insulating against external risk.

Similarly, since the optimal size of the public sector is given by equation (29) and the difference in the size of the public sector by equation (36), the difference between the consumption-wealth ratio in an open economy [equation (31)] and that in a closed economy [equation (34)], that is,

$$
\left(\frac{C}{W}\right)_{o}-\left(\frac{C}{W}\right)_{c}=-0.5 \gamma \Delta n_{d}^{*^{2}}
$$

shows that the consumption-wealth ratio in an open economy will be higher than in a closed economy, for $\gamma<0$, as in Section 3. Analogous results to the case when the size of the public sector was exogenously given apply for the impact of financial openness on the growth rate [see Table 1] and welfare. Thus, the growth rate is higher in a closed economy than in an open economy for similar productivities across countries. Only when the marginal product of foreign capital $\alpha^{*}$ is higher than the marginal product of domestic capital $\alpha$ the opposite may be true. Welfare is unambiguously higher in an open economy.

\section{Data sources}

22 OECD countries for the period 1970-2004: Austria, Australia, Belgium, Canada, Denmark, Finland, France, Germany, Greece, Iceland, Ireland, Italy, Japan, The Netherlands, Norway, New Zealand, Spain, Portugal, Sweden, Switzerland, United Kingdom, and the United States. The data on international investment positions have been obtained from the International Monetary Fund's International Financial Statistics. Additionally, as data on international investment positions are incomplete or missing for many countries (specially before 1980-1986), Lane and Milesi-Ferretti (2007) provide 
an excellent source of data for those years ${ }^{13}$. The data on consumption, size of the public sector, and so on is based on World Bank's World Development Indicators. Broadly speaking, the data required in order to test the results (specially domestic capital, foreign capital, wealth and so on) have been constructed following the procedure by Kraay \& Ventura $(2000)^{14}$.

\section{The empirical evidence}

The model postulates a positive relationship between the optimal size of the public sector (with respect to wealth) and financial openness. The positive association can be tested with the regression equation [see equation (36)]

$$
\left(\frac{G}{W}\right)_{c t}=\alpha+\beta n_{d, c t}^{*}+u_{c t}
$$

where $(G / W)_{c t}$ denotes the consumption-wealth ratio for country $c$ in period $t, n_{d, c t}^{*}$ denotes the portfolio share of foreign capital in domestic wealth for country $c$ in period $t$, and $u_{c t}$ is the error term for country $c$ in period $t$. Under the null hypothesis that a more open economy should have a higher size of the public sector is true then the coefficient $\beta$ should be positive.

Table 2 shows the results by OLS. The point estimate $\beta$ is equal to 0.03 and thus it is positive. Additionally, the between-group estimates (that is, based on the mean values of the variables of the group) and the within-group estimates (also called fixed-effects estimators, that is, in terms of deviations from the mean values of the variables of the group) are shown. The betweengroup and within-group estimates for the coefficient capturing financial openness are also found to be positive. Furthermore, the null hypothesis that the value of the parameter $\beta$ is equal to zero can be rejected, except for the between-group estimate.

Then some control variables are taken into account in the regression. They include population and output per capita (both in levels and growth rates), so that the size of the economy, and also possible pressures on government spending are considered; current account balance (as a percentage of GDP), as a potential influence on the size of the public sector; and a time trend that can capture possible upward or downward movements in economic

\footnotetext{
${ }^{13}$ Please note that most of the data from IMF's IFS and from Lane and Milesi-Ferretti (2007) coincide for recent years.

${ }^{14}$ See Appendix 2 of their work. The data employed in this paper is available at http://paginaspersonales.deusto.es/ineraus/.
} 
variables. The period analyzed is restricted to 1975-2004 due to data availability. When control variables are added to the regression, these variables have, in general, little effect on the pooled estimate of the coefficient $\beta$, as shown in Table 3. Additionally, while the between estimate (positive) is reinforced, results do change only for the within-group estimate.

The result that consumption-wealth ratio is higher in an open economy than in a closed economy can be tested with the regression equation [see equation (26)]

$$
\left(\frac{C}{W}\right)_{c t}=\alpha+\beta n_{d, c t}^{*}+u_{c t}
$$

where $(C / W)_{c t}$ denotes consumption-wealth ratio for country $c$ in period $t, n_{d, c t}^{*}$ denotes the portfolio share of foreign capital in domestic wealth for country $c$ in period $t$, and $u_{c t}$ is the error term for country $c$ in period $t$. Under the null hypothesis that more open economies should have higher consumption-wealth ratios is true then the parameter $\beta$ should be positive.

We show in Table 5 the results of fitting the regression equation by ordinary least squares (OLS). The coefficient $\beta$ is negative but almost zero in the pooled regression. Additionally, whereas we get a positive value of the between estimate, again a negative one is found in the within estimate. On the other hand, the null hypothesis that the parameter value is equal to zero cannot be statistically rejected in any of the three estimates. Once we add control variables to the regression equation, the results of testing change considerably: the estimates of the coefficient $\beta$ are positive in the three regressions, as it is shown in Table 4 . However, the null hypothesis that the coefficient $\beta$ is equal to zero is rejected in the within regression.

\section{Conclusions}

Much time has been devoted to whether more open economies have bigger governments since Rodrik (1998) published his seminal work. Recent studies have even challenged this result. However, most of the research has been focused on trade openness rather than on financial openness, which is restrictive specially when financial markets are increasingly integrated. Recent studies show a negative relationship between financial openness and the size of the public sector due to an increased mobility of inputs (the efficiency hypothesis) rather a positive one (the compensation hypothesis).

This paper offers an alternative view to the relationship between financial openness and some key economic variables, such as the consumption-wealth 
ratio, the growth rate of wealth, welfare, and the optimal size of the public sector, based on a portfolio approach. A central result of the model is that an open economy implies a higher consumption-wealth ratio, lower growth, higher welfare, and a higher size of the public sector than in a closed economy due to the risk diversification achieved in an open economy. The empirical evidence broadly supports the main results of the model. 


\section{A Optimization}

The first step in order to solve the optimization problem in the domestic economy is to introduce a value function, $V(W)$, which is defined as

$$
V(W)=\underset{\left\{C, n_{d}\right\}}{\operatorname{Max}} E_{0} \int_{0}^{\infty} \frac{1}{\gamma}\left(C G^{\eta}\right)^{\gamma} e^{-\beta t} d t
$$

subject to restrictions (10), (11), and (12) and given initial wealth. The value function in period 0 is the expected value of the discounted sum of instantaneous utilities, evaluated along the optimal path, starting in period 0 in the state $W(0)=W_{0}$.

Second, starting from equation (37) the value function must satisfy the following equation, known as the Hamilton-Jacobi-Bellman equation of stochastic control theory or, for short, the Bellman equation

$$
\beta V(W)=\underset{\left\{C, n_{d}\right\}}{\operatorname{Max}}\left[\frac{1}{\gamma}\left(C G^{\eta}\right)^{\gamma}+V^{\prime}(W) W \psi+0.5 V^{\prime \prime}(W) W^{2} \sigma_{w}^{2}\right] .
$$

Third, (38) is partially differentiated with respect to $C$ and $n_{d}$ in order to get the first order optimality conditions of this problem

$$
\begin{aligned}
C^{\gamma-1} G^{\eta \gamma}-V^{\prime}(W) & =0 \\
V^{\prime}(W) W\left(\alpha-\alpha^{*}\right)+V^{\prime \prime}(W) W^{2} \operatorname{cov}\left[d w, \alpha d y-\alpha^{*} d y^{*}\right] & =0 .
\end{aligned}
$$

The solution to this maximization problem is obtained through trial and error. We seek to find a value function $V(W)$ that satisfies, on the one hand, the first order optimality conditions and, on the other, the Bellman equation. In the case of isoelastic utility functions the value function has the same form of the utility function [Merton (1969), generalized in Merton (1971)]. Thus, we guess that the value function is of the form

$$
V(W)=A W^{\gamma(1+\eta)}
$$

where the coefficient $A$ is determined below. That guess implies

$$
\begin{aligned}
V^{\prime}(W) & =A \gamma(1+\eta) W^{\gamma(1+\eta)-1} \\
V^{\prime \prime}(W) & =A \gamma(1+\eta)[\gamma(1+\eta)-1] W^{\gamma(1+\eta)-2}
\end{aligned}
$$


Inserting these expressions into the first order optimality conditions (39) and (40), the result is

$$
\begin{aligned}
C^{\gamma-1} G^{\eta \gamma} & =A \gamma(1+\eta) W^{\gamma(1+\eta)-1} \\
\left(\alpha-\alpha^{*}\right) d t & =[1-\gamma(1+\eta)] \operatorname{cov}\left[d w, \alpha d y-\alpha^{*} d y^{*}\right]
\end{aligned}
$$

Both are typical equations in stochastic models in continuous time. Equation (42) indicates that at the optimum, the marginal utility derived from private consumption must be equal to the marginal change in the value function or the marginal utility of wealth. Equation (43) shows that the optimal choice of portfolio shares must be such that the risk-adjusted rates of return of both domestic and foreign capital are equalized.

Combining (42) and (43), and substituting them in the equation (38), we are able to calculate, after some algebra, the equilibrium portfolio shares and the consumption-wealth ratio in the domestic open economy, shown in equations (13), (14), and (15),

$$
\begin{aligned}
n_{d}= & \frac{\alpha-\alpha^{*}}{[1-\gamma(1+\eta)] \Delta}+\frac{\alpha^{*^{2}} \sigma_{y^{*}}^{2}-\alpha \alpha^{*} \sigma_{y y^{*}}+\alpha \sigma_{y z}-\alpha^{*} \sigma_{y^{*} z}}{\Delta} \\
n_{d}^{*}= & 1-n_{d} \\
\left(\frac{C}{W}\right)_{o}= & \frac{1}{(1-\gamma)(1+\eta)}[\beta-\gamma(1+\eta)(\rho-g) \\
& \left.+0.5 \gamma(1+\eta)[1-\gamma(1+\eta)] \sigma_{w, o}^{2}\right],
\end{aligned}
$$

where

$$
\begin{aligned}
\Delta= & \alpha^{2} \sigma_{y}^{2}-2 \alpha \alpha^{*} \sigma_{y y^{*}}+\alpha^{*^{2}} \sigma_{y^{*}}^{2} \\
\sigma_{w, o}^{2}= & n_{d}^{2} \alpha^{2} \sigma_{y}^{2}+2 n_{d} n_{d}^{*} \alpha \alpha^{*} \sigma_{y y^{*}}+n_{d}^{*^{2}} \alpha^{*^{2}} \sigma_{y^{*}}^{2}+\sigma_{z}^{2} \\
& -2 n_{d} \alpha \sigma_{y z}-2 n_{d}^{*} \alpha^{*} \sigma_{y^{*} z}
\end{aligned}
$$

as they are shown in equations (16) and (17). 


\section{B Second order conditions}

In order to guarantee that consumption is positive in the domestic open economy we impose the feasibility condition that the marginal propensity to consume out of wealth [see equation (15)] must be positive since wealth does not become negative

$$
\begin{aligned}
& \frac{1}{(1-\gamma)(1+\eta)}\{\beta-\gamma(1+\eta)(\rho-g) \\
& \left.+0.5 \gamma(1+\eta)[1-\gamma(1+\eta)] \sigma_{w, o}^{2}\right\}>0
\end{aligned}
$$

For the first order optimality conditions to characterize a maximum, the corresponding second order condition must be satisfied, that is, the Hessian matrix associated to the maximization problem and evaluated at the optimal values of the choice variables

$$
\left[\begin{array}{cc}
(\gamma-1)\left(V^{\prime}(W)\right)^{\frac{\gamma-2}{\gamma-1}} & 0 \\
0 & V^{\prime \prime}(W) W^{2} \Delta
\end{array}\right]
$$

must be negative definite, ${ }^{15}$ which implies that

$$
\begin{aligned}
(\gamma-1)\left(V^{\prime}(W)\right)^{\frac{\gamma-2}{\gamma-1}} & <0 \\
V^{\prime \prime}(W) W^{2} \Delta & <0
\end{aligned}
$$

where $\Delta>0$ (in a risky economy) was already defined in equation (16). To evaluate those conditions, first we obtain the value of the coefficient $A$ in equation (42)

$$
A=\frac{g^{\eta \gamma}}{\gamma(1+\eta)}\left(\frac{C}{W}\right)^{\gamma-1}
$$

where $C / W$ is the optimal value pointed out by equation (15). Then we insert (44) into the value function (41). Noting that $g=G / W$, the value

\footnotetext{
${ }^{15}$ See Chiang (1984, pp. 320-323), for example.
} 
function is given, after some algebra, by

$$
V(W)=\frac{g^{\eta \gamma}}{\gamma(1+\eta)}\left(\frac{C}{W}\right)^{\gamma-1} W^{\gamma(1+\eta)},
$$

where we can observe that, given the restrictions on the utility function, $V^{\prime}(W)>0$ and $V^{\prime \prime}(W)<0$ provided that $C / W>0$.

In addition, we impose that the macroeconomic equilibrium must satisfy the transversality condition so as to guarantee the convergence of the value function

$$
\lim _{t \rightarrow \infty} E\left[V(W) e^{-\beta t}\right]=0 .
$$

Now let us show that should the feasibility condition be satisfied, that would be equivalent to satisfy the transversality condition. ${ }^{16}$ To evaluate (46), we start expressing the dynamics of the accumulation of wealth

$$
d W=\psi W d t+W d w .
$$

The solution to equation (47), starting from the initial wealth $W(0)$, is ${ }^{17}$

$$
W(t)=W(0) e^{\left(\psi-0.5 \sigma_{w}^{2}\right) t+w(t)-w(0)} .
$$

Since the increments of $w$ are temporally independent and are normally distributed then ${ }^{18}$

$$
\begin{aligned}
E\left[A W^{\gamma(1+\eta)} e^{-\beta t}\right] & =E\left[A W(0)^{\gamma(1+\eta)} e^{\gamma(1+\eta)\left(\psi-0.5 \sigma_{w}^{2}\right) t+\gamma(1+\eta)[w(t)-w(0)]-\beta t}\right] \\
& =A W(0)^{\gamma(1+\eta)} e^{\left[\gamma(1+\eta)\left(\psi-0.5 \sigma_{w}^{2}\right)+0.5 \gamma^{2}(1+\eta)^{2} \sigma_{w}^{2}-\beta\right] t}
\end{aligned}
$$

The transversality condition (46) will be satisfied if and only if

$$
\gamma(1+\eta)\left\{\psi-0.5 \gamma(1+\eta)[1-\gamma(1+\eta)] \sigma_{w}^{2}\right\}-\beta<0 .
$$

Now substituting equations (11) and (15), it can be shown that this condition is equivalent to

\footnotetext{
${ }^{16}$ See Merton (1969). Turnovsky (2000) provides, for example, the proof of the transversality condition as well.

${ }^{17}$ See Malliaris and Brock (1982, pp. 135-136), for example.

${ }^{18}$ See Malliaris and Brock (1982, pp. 137-138), for example.
} 


$$
\frac{C}{W}>0,
$$

and thus feasibility guarantees convergence as well.

Finally, it should be noted that since the public sector equilibrates its budget continuously, the intertemporal budget constraint of the public sector is satisfied trivially. 


\section{References}

[1] Alesina, A., Wacziarg, R., 1998. Openness, country size and government. Journal of Public Economics 69, 305-321.

[2] Barro, R.J., 1990. Government spending in a simple model of endogenous growth. Journal of Political Economy 98, S103-S125.

[3] Cameron, D., 1978. The expansion of the public economy: a comparative analysis, American Political Science Review, 72, 1243-61.

[4] Campbell, J.Y., 1996. Understanding risk and return. Journal of Political Economy 104, 298-345.

[5] Chiang, A.C., 1984. Fundamental methods of mathematical economics, Third edition. McGraw-Hill, Singapore.

[6] Devereux, M.B., Smith, G.W., 1994. International risk sharing and economic growth. International Economic Review 35, 535-550.

[7] Devereux, M.B., Saito, M., 1997. Growth and risk-sharing with incomplete international assets markets. Journal of International Economics $42,453-481$.

[8] Islam, M.Q. (2004). The long run relationship between openness and government size, Applied Economics, 36, 995-1000.

[9] Kamien, M.I., Schwartz, N.L., 1991. Dynamic optimization, Second edition. North-Holland, New York.

[10] Kim, S.Y., 2007. Openness, external risk, and volatility: implications for the compensation hypothesis. International Organization 61, Winter, $181-216$.

[11] Kraay, A. and Ventura, J., 2000. Current accounts in debtor and creditor countries, Quarterly Journal of Economics, 115, 1137-1166.

[12] Lane, Philip R., and Milesi-Ferretti, G.M., 2007. The external wealth of nations mark II: Revised and extended estimates of foreign assets and liabilities, 1970-2004, Journal of International Economics, 73, 223-250. Data available from http://www.philiplane.org/papers.html.

[13] Liberati, P., 2007. Trade openness, capital openness and government size. Journal of Public Policy, 27(2), 215-247. 
[14] Malliaris, A.G., Brock, W.A., 1982. Stochastic methods in economics and finance. North-Holland, Amsterdam.

[15] Merton, R.C., 1969. Lifetime portfolio selection under uncertainty: the continuous-time case. Review of Economics and Statistics 51, 247-257, reprinted in: R.C. Merton, 1992. Continuous-time finance. Blackwell, Massachusetts, pp. 97-119.

[16] Merton, R.C., 1971. Optimum consumption and portfolio rules in a continuous-time model. Journal of Economic Theory 3, 373-413, reprinted in: R.C. Merton, 1992, Continuous-time finance. Blackwell, Massachusetts, pp. 120-165.

[17] Obstfeld, M., 1992. Dynamic optimization in continuous-time economic models (a guide for the perplexed). Working paper, Department of Economics, University of California at Berkeley, available from website http://elsa.berkeley.edu/ obstfeld/index.shtml.

[18] Obstfeld, M., 1994. Risk-taking, global diversification, and growth. American Economic Review 84, 1310-1329.

[19] Obstfeld, M., Taylor, A.M., 2004. Global capital markets. Integration, crisis, and growth. Cambridge University Press, United Kingdom.

[20] Rodrik, D., 1998. Why do more open economies have bigger governments?. Journal of Political Economy 106, 997-1032.

[21] Schulze, G., Ursprung, H.W., 1999. Globalization of the economy and the Nation State. The World Economy, 22, 295-352.

[22] Turnovsky, S.J., 1996. Fiscal policy, growth, and the macroeconomic performance in a small open economy. Journal of International Economics 40, 41-66.

[23] Turnovsky, S.J., 1997. International macroeconomic dynamics. MIT Press, Cambridge.

[24] Turnovsky, S.J., 1999. On the role of government in a stochastically growing open economy. Journal of Economic Dynamics and Control 23, 873-908.

[25] Turnovsky, S.J., 2000. Methods of macroeconomic dynamics, Second edition. MIT Press, Cambridge. 
Table 1: Comparing growth rates

\begin{tabular}{|c|c|c|c|}
\hline & $\gamma>0$ & $\gamma=0$ & $\gamma<0$ \\
\hline$\alpha>\alpha^{*}$ & $\psi_{o} \lesseqgtr \psi_{c}$ & $\psi_{o}<\psi_{c}$ & $\psi_{o}<\psi_{c}$ \\
\hline$\alpha=\alpha^{*}$ & $\psi_{o}>\psi_{c}$ & $\psi_{o}=\psi_{c}$ & $\psi_{o}<\psi_{c}$ \\
\hline$\alpha<\alpha^{*}$ & $\psi_{o}>\psi_{c}$ & $\psi_{o}>\psi_{c}$ & $\psi_{o} \lesseqgtr \psi_{c}$ \\
\hline
\end{tabular}


Table 2: Openness and the size of the public sector

\begin{tabular}{cccc}
\hline & $\begin{array}{c}\text { Pooled } \\
\text { regression }\end{array}$ & $\begin{array}{c}\text { Between } \\
\text { regression }\end{array}$ & $\begin{array}{c}\text { Within } \\
\text { regression }\end{array}$ \\
\hline Portfolio share & $\begin{array}{c}0.0302 \\
(0.0057)\end{array}$ & $\begin{array}{c}0.0801 \\
(0.0527)\end{array}$ & $\begin{array}{c}0.0141 \\
(0.0043)\end{array}$ \\
\hline$R^{2}$ & 0.0357 & 0.1038 & 0.5964 \\
\hline No. of observations & 766 & 22 & 766 \\
\hline
\end{tabular}

Standard errors are in parenthesis.

Sources: IFS (IMF), WDI (WB), Lane and Milesi-Ferretti (2007), and own elaboration.

Table 3: Openness and the size of the public sector (with control variables)

\begin{tabular}{cccc}
\hline & $\begin{array}{c}\text { Pooled } \\
\text { regression }\end{array}$ & $\begin{array}{c}\text { Between } \\
\text { regression }\end{array}$ & $\begin{array}{c}\text { Within } \\
\text { regression }\end{array}$ \\
\hline Portfolio share & 0.03086 & 0.1279 & -0.0010 \\
& $(0.0073)$ & $(0.0518)$ & $(0.0074)$ \\
Time trend & 0.0002 & & 0.0009 \\
& $(0.0001)$ & & $(0.0002)$ \\
Current account (\%GDP) & -0.1875 & -0.6121 & -0.0946 \\
& $(0.0249)$ & $(0.2110)$ & $(0.0201)$ \\
Population & $-7.04 \mathrm{E}-11$ & $-7.06 \mathrm{E}-11$ & $-1.41 \mathrm{E}-10$ \\
Population growth & $(1.58 \mathrm{E}-11)$ & $(6.52 \mathrm{E}-11)$ & $(1.21 \mathrm{E}-10)$ \\
& -0.0052 & -0.0213 & 0.0023 \\
GDP per capita & $(0.0018)$ & $(0.0119)$ & $(0.0017)$ \\
& $-1.21 \mathrm{E}-08$ & $2.24 \mathrm{E}-06$ & $-9.52 \mathrm{E}-07$ \\
GDP per capita growth & $(2.61 \mathrm{E}-07)$ & $(1.47 \mathrm{E}-06)$ & $(4.84 \mathrm{E}-07)$ \\
& -0.0002 & 0.0017 & -0.0002 \\
$R^{2}$ & $(0.0004)$ & $(0.0055)$ & $(0.0003)$ \\
\hline No. of observations & 0.1570 & 0.4700 & 0.6307 \\
\hline
\end{tabular}

Standard errors are in parenthesis.

Sources: IFS (IMF), WDI (WB), Lane and Milesi-Ferretti (2007), and own elaboration. 
Table 4: Openness and consumption-wealth ratio

\begin{tabular}{cccc}
\hline & $\begin{array}{c}\text { Pooled } \\
\text { regression }\end{array}$ & $\begin{array}{c}\text { Between } \\
\text { regression }\end{array}$ & $\begin{array}{c}\text { Within } \\
\text { regression }\end{array}$ \\
\hline Portfolio share & -0.0007 & 0.0354 & -0.0133 \\
& $(0.0153)$ & $(0.1410)$ & $(0.0120)$ \\
\hline$R^{2}$ & 0.000003 & 0.0031 & 0.5429 \\
\hline No. of observations & 765 & 22 & 765 \\
\hline
\end{tabular}

Standard errors are in parenthesis.

Sources: IFS (IMF), WDI (WB), Lane and Milesi-Ferretti (2007), and own elaboration.

Table 5: Openness and consumption-wealth ratio (with control variables)

\begin{tabular}{cccc}
\hline & $\begin{array}{c}\text { Pooled } \\
\text { regression }\end{array}$ & $\begin{array}{c}\text { Between } \\
\text { regression }\end{array}$ & $\begin{array}{c}\text { Within } \\
\text { regression }\end{array}$ \\
\hline Portfolio share & 0.0886 & 0.2510 & 0.0023 \\
Time trend & $(0.0165)$ & $(0.0673)$ & $(0.0210)$ \\
& 0.0026 & & 0.0022 \\
Current account (\%GDP) & $(0.0003)$ & & $(0.0005)$ \\
& -0.4804 & -1.3110 & -0.1963 \\
Population & $(0.0565)$ & $(0.2741)$ & $(0.0571)$ \\
& $2.30 \mathrm{E}-10$ & $1.93 \mathrm{E}-10$ & $1.45 \mathrm{E}-09$ \\
Population growth & $(3.57 \mathrm{E}-11)$ & $(8.47 \mathrm{E}-11)$ & $(3.43 \mathrm{E}-10)$ \\
& 0.0186 & -0.0129 & 0.0229 \\
GDP per capita & $(0.0041)$ & $(0.0155)$ & $(0.0047)$ \\
& $-6.74 \mathrm{E}-06$ & $-2.50 \mathrm{E}-06$ & $-4.86 \mathrm{E}-06$ \\
GDP per capita growth & $(5.91 \mathrm{E}-07)$ & $(1.91 \mathrm{E}-06)$ & $(1.37 \mathrm{E}-06)$ \\
& -0.0028 & 0.0149 & 0.0017 \\
$R^{2}$ & $(0.0009)$ & $(0.0071)$ & $(0.0008)$ \\
\hline No. of observations & 0.3935 & 0.8613 & 0.5829 \\
\hline
\end{tabular}

Standard errors are in parenthesis.

Sources: IFS (IMF), WDI (WB), Lane and Milesi-Ferretti (2007), and own elaboration. 